\title{
AULA TEÓRICA: QUANDO UTILIZAR?
}

\author{
LECTURE - WHEN TO USE?
}

Antonio Pazin Filho

Docente. Departamento de Clinica Médica. Faculdade de Medicina de Ribeirão Preto - USP.

Correspondência: Centro de Estudos de Emergências em Saúde - CEES. Rua Bernardino de Campos, 1.000

14.015-130 Ribeirão Preto - SP. apazin@fmrp.usp.br

Pazin Filho A. Aula teórica: quando utilizar? Medicina (Ribeirão Preto) 2007; 40 (1): 3-6.

RESUMO: Este artigo tem a finalidade de contextualizar a aula teórica dentro das diversas modalidades disponíveis de recursos didáticos e expor os fatores que devem ser levados em consideração para quando se optar pela aula teórica. Basicamente estes fatores podem ser divididos naqueles concernentes aos objetivos da atividade, às características da platéia e do palestrante.

Descritores: Aula teórica; seleção de recursos. Educação Médica.

"Não sou eu que mato as aulas. As aulas é que me matam."

Aaron Sutton

\section{1- INTRODUÇÃO}

A aula teórica é um dos instrumentos mais utilizados em didática. É um recurso tão arraigado na nossa cultura de ensino que muitas vezes confundimos ensino com aula teórica. Diversas características garantem esta preferência, mas não implicam que ela seja o melhor recurso para qualquer atividade. Este artigo tem a finalidade de contextualizar a aula teórica dentro das diversas modalidades disponíveis e expor os fatores que devem ser levados em consideração para quando se optar pela aula teórica como recurso didático. Basicamente estes fatores podem ser divididos naqueles concernentes aos objetivos da atividade, às características da platéia e do palestrante.

\section{2- OBJETIVO A SER TRANSMITIDO}

Os objetivos podem ser de natureza diversa como está exemplificado na Figura 1. Um primeiro componente diz respeito ao plano cognitivo de conhecimento, no qual se pretende passar conceitos, definições, mecanismos de ação, informações sobre tratamento, etc. A aula teórica é extremamente adequada para este tipo de finalidade. O segundo componente é a competência, no qual o indivíduo deve ter não só o conceito, mas adquirir os princípios de habilidade para demonstrar como fazer. A este segue-se a performance, no qual o indivíduo não só tem conhecimento e sabe como deverá proceder, mas é capaz de mostrar como fazer. Por fim, está a ação propriamente dita, na qual o indivíduo efetivamente realiza a habilidade. Competência, performance e ação são habilidades melhor transmitidas por outras técnicas de ensino.

Para melhor compreender o que se pretende transmitir na Figura 1, tomemos um procedimento cirúrgico como a colecistectomia por exemplo. Para que alguém possa realizá-lo é necessário todo o conhecimento sobre anatomia, material cirúrgico, técnica a ser empregada, complicações potenciais, etc. Estas informações são a base de qualquer ensinamento e por isso representadas na Figura 1 como a base da pirâmide. Não significa dizer que os outros componentes da pirâmide não sejam tão importantes ou 


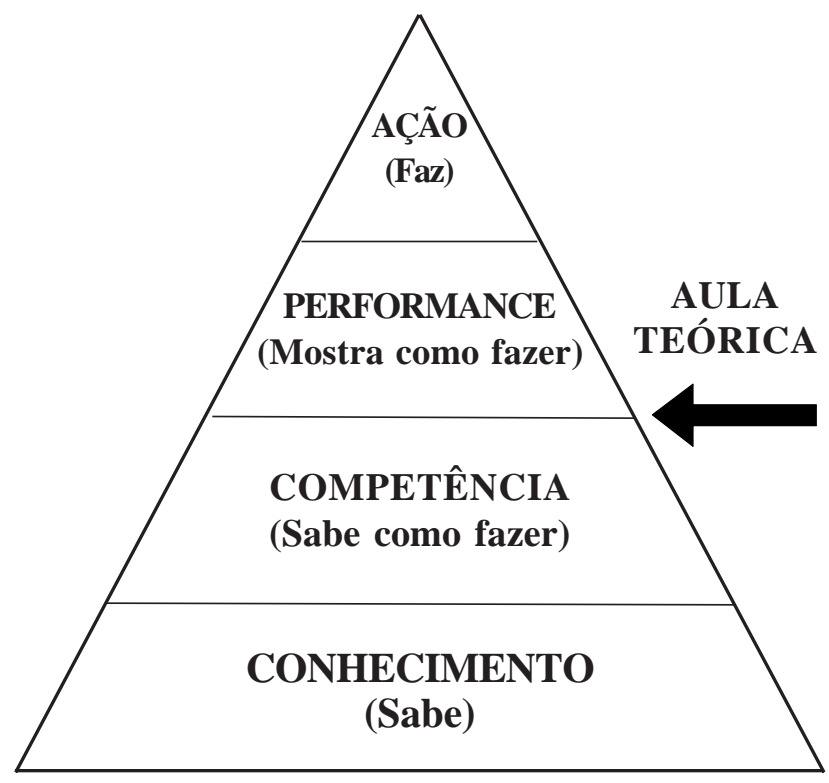

Figura 1: Diversos componentes dos objetivos a serem transmitidos. Adaptado de Miller GE (1990)

difícieis de se adquirir, mas são etapas sucessivas. Além do conhecimento sobre colecistectomia, antes de efetivamente realizar o procedimento o aluno deverá saber como proceder, quais os passos, em que sequiência, etc. Isto é o que se entende como competência. Segue-se a isto a capacidade do aluno em demonstrar como fazer em modelos animais de experimentação, a performance. Por fim, após todas estas fases, ele pode ser tutorado em atividade real, sob supervisão, mas efetivamente realizando o procedimento.

Não significa dizer que a aula teórica não possa abordar informação concernente aos demais planos, mas que será muito menos efetiva. Da mesma forma, técnicas voltadas para a performance como a simulação em manequins serão muito menos eficazes como transmissão de informação e irão requerer muito mais tempo se desprovidas do conteúdo. Neste sentido, várias técnicas devem ser combinadas para que se atinja a transmissão completa da informação desejada.

Os recentes avanços das técnicas de ilustração em recursos didáticos têm permitido associar filmes, esquemas e figuras que favorecem em muito a transmissão de informação, possibilitando que se extenda o uso da aula teórica para o ensino de competência, mas mesmo estes recursos não possibilitam o ensino de performance e ação. Embora este simpósio trate principalmente da aula teórica presencial, ou seja, na qual o palestrante e a platéia estão presentes fisicamente, os novos recursos de internet e video- conferência estão possibilitando a tele-presença. Para estas atividades, ainda não se dispõe de informação definitiva sobre sua capacidade de transmissão de conhecimento, mas infere-se que tenham as mesmas limitações, ou sejam até mais limitadas, que as técnicas presenciais.

Mesmo quando a informação a ser transmitida é preferencialmente do plano cognitivo (conhecimento), a aula teórica não é a única técnica que pode ser empregada (vide Tabela 1). Ao contrário da ação, performance e competência que são limitados em técnicas disponíveis, diversos tipos de atividade didática foram desenvolvidos para transmissão de conhecimento cognitivo, principalmente para tentar compensar a principal deficiência da aula téorica que é a baixa retenção do que é transmitido (vide capítulo sobre Conteúdo). No entanto, a aula teórica ainda persiste muito prevalente em virtude de algumas características.

Tabela I - Técnicas disponíveis para transmissão de informação de acordo com o plano de informação a ser alcançado

\begin{tabular}{ll}
\hline Plano de Informação & Técnicas Disponíveis \\
\hline $\begin{array}{l}\text { Ação/ Performance/ } \\
\text { Competência }\end{array}$ & $\begin{array}{l}\text { Aulas Práticas } \\
\text { Simulação } \\
\text { Demonstrações }\end{array}$ \\
& Aula Teórica \\
Ceminários \\
Discussão de Grupo \\
Trabalhos de Revisão \\
Estudos Programados
\end{tabular}

Uma grande vantagem da aula téorica sobre as demais técnicas de transmissão de conhecimento está na velocidade de transmissão da informação. As demais técnicas exigem tempo para elaboração do conteúdo e apresentação, enquanto a aula teórica é previamente preparada pelo palestrante, o que permite maior quantidade de informação em menor tempo.

Outro ponto fundamental é que técnicas como seminários e elaboração de trabalhos requerem fontes de conhecimento muito bem sedimentadas e de 
fácil acesso para elaboração. Não é vital a interpretação do responsável pela atividade, pois se pressupõe que os alunos deverão ser capazes exatamente deste grau de elaboração e, portanto, no preparo da atividade, selecionamos temas que favoreçam este tipo de elaboração para o nível dos nossos alunos. Quando se quer transmitir a informação num grau de maior elaboração, principalmente quando se quer fornecer informação que foi coletada de várias fontes e que não estão prontamente disponíveis para todos ou quando se pretende demonstrar como o palestrante pondera o assunto, a atividade se restringe praticamente à aula teórica. A aula é uma excelente oportunidade para contextualizar informações aparentemente díspares de fontes diversas.

A aula teórica também é muito bem empregada quando se pretende explicar conceitos difícieis e fornecer diretrizes para o estudo de uma determinada população. No desenvolvimento de conteúdo dos diversos programas de ensino, geralmente nos deparamos com pontos que são críticos para o entendimento e que irão requerer muito tempo de elaboração por parte dos nossos alunos. Estas áreas em particular são muito bem contempladas por aulas teóricas. Ainda neste conceito, algumas vezes pretendemos não só passar um conceito, mas estimular o questionamento sobre determinado assunto, desafiando nossos alunos a modificarem sua visão sobre o problema.

Um motivo mais mundano para a grande aceitação da aula teórica é que ela é muito mais econômica que as outras modalidades, que envolvem grande gasto de material. A aula teórica pode ser obtida com "giz e saliva"!

Não se constitui no objetivo deste artigo discorrer sobre todas as modalidades disponíveis para ensino, ilustradas na Tabela I. Cabe, no entanto, o estímulo para aqueles que se interessem por Didática ou se envolvam com atividades de ensino, que se familiarizem com estas técnicas e se aventurem com seu uso. Muita da decepção que enfrentamos com uma aula teórica mal sucedida advem do fato de estarmos usando o recurso errado para atingir um determinado objetivo. O conhecimento destas técnicas pode oferecer oportunidades para se contornar as inúmeras limitações de uma aula teórica, principalmente no que diz respeito à retenção do conhecimento transmitido. A falta de familiaridade destes outros métodos pode ser um dos fatores que limitam sua inclusão nos diversos currículos, excessivamente baseados em atividades passivas como a aula teórica.

\section{3- CARACTERÍSTICAS DA PLATÉIA}

Ao se elaborar uma atividade de ensino, não só os diversos objetivos a serem atingidos podem ser levados em consideração. Tudo o que é elaborado deve ser feito com uma respectiva população em mente. De posse de quais são nossos objetivos e quais campos da Figura 1 queremos abranger na atividade a ser desenvolvida, precisamos ver quais as condições reais de trabalho que teremos. Podemos querer abordar como objetivo a transmissão de performance sobre um determinado procedimento, que implica, em condições adequadas de trabalho, pequenos grupos de alunos, com tempo prévio para leitura e elaboração de material. Mas quando nos deparamos com a situação real, nosso tempo é limitado e o número de pessoas que devemos trabalhar é um grande grupo, o que nos obriga a selecionar um recurso que possa atingir esta população. Assim, ao invés de selecionar uma aula prática, com modelos animais ou técnicas de simulação, nos vemos restritos à aula teórica.

Esta é uma característica da aula teórica que a torna tão popular. Ela é extremamente útil quando se quer transmitir informação para uma grande quantidade de pessoas em pouco espaço de tempo.

\section{4- CARACTERÍSTICAS DO PALESTRANTE}

Talvez o mais importante dos três componentes apresentados seja o palestrante. Podemos estar no campo adequado de objetivos a serem transmitidos, sendo a aula teórica o melhor recurso disponível e a platéia ser totalmente adequada, mas se o palestrante não se sente confortável com as habilidades necessárias para que possa falar em público e ensinar através deste recurso, tudo será em vão.

Alguns acreditam que esta habilidade do palestrante seja algo intrínseco e utilizam isto como desculpa por não serem capazes de apresentar uma aula teórica. É lógico que algumas pessoas serão mais propensas a desenvolverem este tipo de atividade por características de personalidade, mas estas habilidades estão longe de serem algo "congênito". Estas habilidades podem ser aprendidas, embora seja necessário dedicação e estudo. Este simpósio tem a pretensão de fornecer elementos para auxiliar na aquisição destas habilidades.

Outra crença comum é a associação de que para ser um bom apresentador, devemos nos tornar semelhantes a um conceito ideal de professor. Alguns 
associam este modelo a uma pessoa que conta muitas histórias engraçadas durante uma apresentação, ou ao modelo austero, extremamente respeitável, que transmite a imagem de "fonte de conhecimento". Isto não é necessário, sendo inclusive não recomendável. Não é necessário que se modifique o seu jeito de ser para se tornar um bom transmissor de informação. É possível transmitir uma informação sem "contar uma piada".

Uma crença final diz respeito à que "dar aula é uma arte". Esta afirmação tem algo de correto, mas leva a uma interpretação errônea que deve ser corrigida. O ponto correto é que podemos entender "arte" como algo manufaturado e fruto da criatividade de quem a elabora, o que é muito acertado como será demonstrado no capítulo sobre Conteúdo. O ponto incorreto que deve ser corrigido diz respeito à noção de que sendo uma "arte", não há estudo científico sobre aula teórica. Na verdade, a aula teórica é uma atividade de comunicação e neste sentido é estudada em áreas como psicologia, negociação, retórica e lógica. Por ser uma atividade não relacionada à nossa área direta de conhecimento, não estamos atentos para a enorme quantidade de informação disponível.

Para falar a verdade, a quantidade de informação é tamanha e tão variada que é extremamente difícil filtrar os conceitos necessários para as nossas necessidades. Alguns dos conceitos que necessitamos são gerais, enquanto outros são muito restritos para o tipo de atividade que ensinamos e o tipo de população com que trabalhamos. Para algumas das nossas necessidades, não há muita informação disponível, o que abre a oportunidade para que geremos conhecimento através de pesquisa sistemática na área.

Pazin Filho A. Lecture - When to use?. Medicina (Ribeirão Preto) 2007; 40 (1): 3-6.

ABSTRACT: This article will contextualize the lecture among the several available modalities of teaching resources and give the issues that have to be taken into consideration to select the lecture. Basically, these issues can be categorized concerning the objectives, those concerning the persons the activity is developed for and those related to the presenter.

Keywords: Lecture; selecting resources. Education, Medical.

\section{REFERENCIAS CONSULTADAS}

1 - Alley M. The craft of scientific presentations: critical steps to succeed and critical errors to avoid. Blacksburg, VA: Springer; 2003.

2 - Galbraith MW. Adult learning methods: a guide for effective instruction. 1st ed. Malabar, FL: Robert E. Krieger Publishing; 1990.

3 - Instructor's manual for advanced cardiac life support. 2nd ed. Dallas, Tex: American Heart Association; 1988.
4 - Miller GE. The assessment of clinical skills/competence/performance. Acad Med 1990; 65(9 Suppl):S63-S67.

5 - Rogers A. Teaching adults. 3rd ed. Philadelphia, PA: Open University Press; 2002.

Recebido em 07/11/2006

Aprovado em 13/03/2007 